\title{
ACUTE PANCREATITIS AND RENAL
}

\section{FAILURE}

\author{
H. A. LEE, B.Sc., M.B., B.S., M.R.C.P. \\ Lecturer in Medicine \\ *E. A. Hills, M.B., M.R.C.P. \\ Registrar
}

Department of Medicine, King's College Hospital Medical School, S.E.5.

ACUTE oliguric renal failure complicating acute pancreatitis is rare and many standard texts fail to mention it. Russell Taylor (1949) found it only once in 110 such patients, and in 163 examined post mortem Blumenthal and Probstein (1959) found only one case where a lower nephron nephrosis seemed to be related to postoperative haemorrhage and shock, although albuminuria without evidence of further renal damage is not infrequent in acute pancreatitis (Siler and Wulsin, 1951). However, Balslov, Jorgensen and Nielsen described thirteen examples of renal failure in 1962 and reviewed 27 others from the world literature. The aetiology is not well understood, but causes such as shock (Beisel, Herndon, Myers and Stones, 1959), dehydration (Ducrot and Slama, 1960), anoxia (Beisel and others, 1959), bouts of fever (Edlund, 1950), fat emboli in glomerular capillary tufts (Lynch, 1954) and thrombi in renal vessels (Ducrot and Slama, 1960) have been suggested.

Ducrot and Slama (1960) found acute pancreatitis as the cause of renal failure in seven of 400 patients with acute renal failure and Balslov and others (1962) found thirteen in their series of 300 . Among 30 patients with acute pancreatitis admitted to the hospital over the past ten years none had acute renal failure. Four recent examples are described here who developed renal failure in the absence of any of the known causative factors mentioned above, and which was not recognized in two instances until late in the course of the patients' illness. The nature of the renal lesion is discussed.

\section{Case Reports}

Case No. 1

This 52-year-old male was admitted to hospital on 5.9.64 some ten hours after injury in a motor-car

\section{* Present Address:}

Medical Registrar, St. Mary's Hospital, Paddington, London. accident in which a van which he was driving was hit in the rear. His abdomen struck the steering wheel on impact. He had gone home following the accident, feeling alright, though a little shaken. On admission he complained of lower abdominal pain and had had difficulty in micturition for six hours.

On examination B.P. $140 / 90 \mathrm{~mm}$. Hg., pulse rate 60; scattered rhonchi were heard in the chest. There was lower abdominal tenderness but bowel sounds were present. Urine: S.G. 1018, a trace of albumin, reaction acid. Hb $102 \%$.

Operation. A few hours after admission his pulse rate rose to 80 and he had a laparotomy to exclude bleeding. A haematoma was found around the pancreas extending into the small bowel mesentery. There was a small tear in the body of the pancreas. The small bowel was in spasm with associated pallor thought to be of autonomic origin. His post-operative course was satisfactory, though he had a variable pulse between 100 and 120 and continued to drain clear yellow fluid from a drain. Gastric suction and intravenous fluid therapy were maintained. His 24 hour urine volumes over the next eight days were $900,700,580,300,680,1100$, 400 and $280 \mathrm{ml}$. On 8.9 .64 his blood urea was $130 \mathrm{mg} . / 100 \mathrm{ml}$., plasma bicarbonate $25 \mathrm{mEq} . / 1$ and serum potassium $5.1 \mathrm{mEq} . / 1$.

He was transferred to this Unit on 11.9 .64 because of a rapid deterioration in his clinical state and increasing uraemia. Examination now showed an ill, tired, dehydrated patient with a blood pressure of $170 / 85$, pulse rate of 110 and bilateral coarse basal crepitations with inspiratory rhonchi widespread over the chest. He was expectorating dark brown purulent sputum. There was abdominal distension with lateral tenderness: bowel sounds were present and clear yellow fluid was still drainihg. Bilateral bluish patches discoloured the flanks (GreyTurner sign). Neither myoglobin nor haemoglobin could be found on spectroscopic examination of the urine. The urine urea was $300 \mathrm{mg} . / 100 \mathrm{ml}$. and the S.G. 1009. Serum sodium 121 , potassium 6.7 , plasma bicarbonate $14 \mathrm{mEq} . / 1$. blood urea $550 \mathrm{mg} . / 100 \mathrm{ml}$. Serum amylase 550 units $/ \mathrm{ml}$. Hb $96 \%$, PCV $47 \%$, WBC 17,300 (93\% neutrophils). Serum calcium $8.0 \mathrm{mg} . / 100 \mathrm{ml}$., total serum protein $7.2 \mathrm{~g} . / 100 \mathrm{ml}$.

$\mathrm{He}$ was given a five-hour haemodialysis on the Kolff Twin Coil with satisfactory electrolyte adjustment. During dialysis he complained of severe central abdominal pain which was partly relieved by 'Trasylol'. In the early hours of the following morning his blood pressure fell and the fluid draining was now blood-stained. It was assumed he had another leak from the pancreas. Soon after he developed pulmonary oedema and a tracheostomy 
became necessary. He improved immediately with a better colour and his blood pressure rose to 140/90. But he died suddenly next day.

Necropsy: The peritoneal cavity contained 10 ounces of blood-stained fluid and areas of fat necrosis were scattered throughout the omentum and peritoneal fat tissues. The pancreas was intensely inflamed and showed severe patchy necrosis. The body of the pancreas showed a $2^{\prime \prime}$ tear in its substance. The small bowel mesentery showed a $2^{\prime \prime}$ area of recent bruising. No: gallstones were found. There was a moderate-sized area of internal laceration of the spleen near its hilum. Histologically the kidneys showed changes of tubular necrosis. No micro-emboli were seen.

\section{Case No. 2}

A 62-year-old housewife vomited and passed three loose stools following a pork meal. One hour later she developed severe right epigastric pain which persisted until she was admitted to hospital two days later. There was no further vomiting or diarrrhoea. She had suffered from post-prandial distension for many years. She drank alcohol occasionally.

On Examination she was a pale, fat, dehydrated woman with a temperature of $97^{\circ} \mathrm{F}$. She was in pain and her respiratory rate was increased. The abdomen was distended with marked epigastric tenderness and guarding. Bowel sounds were heard. B.P. $130 / 80$, Hb $90 \%$, WBC 12,300 (80\% polymorphs).

Operation. At laparotomy there was blood-stained peritoneal fluid, areas of fat necrosis and firm enlargement of the oedematous pancreas.

She passed only $150 \mathrm{ml}$. of urine, S.G. 1011, during the 32 hours after admission, and remained oliguric until the seventh day of her illness. On the day following laparotomy she developed pulmonary and peripheral oedema, was cyanosed and dyspnoeic and became hypotensive. Her blood pressure was restored by hydrocortisone and metaramerol, and maintained at over $100 \mathrm{~mm}$. systolic pressure. On the second post-operative day a tracheostomy was done for respiratory distress. Her lblood urea on this day was $152 \mathrm{mg} . / 100 \mathrm{ml}$. , and three days later was 350 mg./100 ml. Her serum amylase was 4,200 Somogyi units \%. Althought her urine output improved on the seventh day, she died suddenly that day.

Necropsy showed haemorrhage and necrosis in the pancreas. There was a double left ureter and the kidneys and lungs were oedematous. Histology of kidney tissue showed disorganisation of tubular epithelium, but it was not possible to say how much of this was due to post-mortem change.

\section{Case No. 3}

This 49-year-old Ceylonese woman had suffered for many years from attacks of wheezing precipitated by respiratory infections. On 10.8 .64 she developed another attack and three days later had right sided pleuritic pain. She was improved by treatment with tetracycline but on 16.8.64 she had diarrhoea, epigastric discomfort and vomiting. The following day she had severe constant left upper abdominal pain and was admitted to hospital for surgical observation. She was asymptomatic for two days and on 23.8.64 was transferred to another hospital under medical care.

On Examination, she was pale; pulse $120 / \mathrm{min}$. B.P. $170 / 105$. There were coarse crepitations over the right lung base, dullness to percussion over the right hypochondrium and diffuse discomfort on palpation of the abdomen. $\mathrm{Hb} 75 \%$, blood urea $120 \mathrm{mg} . / 100$ ml. A chest X-ray showed patchy pneumonic changes at both bases. Resolving pneumonia was diagnosed, and she was treated with penicillin, streptomycin, Phenergan and 'Amesec' for four days.

The following day she had further severe abdominal pain associated with generalised tenderness, maximal in the left iliac fossa and over the liver. Bouts of abdominal pain with slight vomiting recurred and she became confused and unco-operative. A variable pyrexia, a tachycardia, dyspnoea and increasing abdominal distension followed. By 23.8.64 she had o diminished breath sounds and crepitations over both $\vec{\circ}$ lung bases. On 25.8.64 she had deteriorated, was still dyspnoeic, and had been constipated for 36 hours. A straight X-ray of the abdomen showed distended bowel loops. Hb 59\%, PCV 28\%, blood urea 139 mg. $/ 100 \mathrm{ml}$. Liver function tests were normal. Amoebic hepatitis was suspected and a trial of $\stackrel{3}{?}$ emetine and chloroquine was started. Cloxacillin is and tetracycline were given additionally on 27.8.64. As a result of continued vomiting she became severely dehydrated: gastric suction and intravenous fluids were started with an intake of 5 litres per day. Marked positive fluid balance occurred and by $\neg$ 28.8.64 she developed pulmonary oedema and 은 anasarca. Chlorothiazide did not produce a diuresis. She was transferred to the Kidney Unit on 29.8.64.

On Examination she was afebrile, pale, wasted, anxious and very dyspnoeic with gross anasarca. Her pulse was regular, 140 per minute; B.P. 80/60, JVP raised to the angle of the jaw. Pericardiat friction was heard. She had signs of pulmonarg oedema and basal consolidation. The abdomen was. distended, diffusely tender and bowel sounds werg. present. Hb 47\%, PCV 26\%, WBC 15,600 (96\% neutrophils), blood urea $160 \mathrm{mg} / 100 \mathrm{ml}$., serum sodium 133, potassium 4.7, plasma bicarbonate 15 mEq./1., serum calcium 8.0, phosphate $6.5 \mathrm{mg} /$ $100 \mathrm{ml}$., amylase 160 Somogyi units. Liver function tests were normal and blood cultures sterile. There was verdiglobinuria and moderate albuminuria. Urine osmolarity was $280 \mathrm{mOsm}$. $/ \mathbf{k g}$. and urine urea $510 \mathrm{mg} . / 100 \mathrm{ml}$. Urine microscopy showed numerous red blood cells, a few white blood cells, and a few organisms. Coliforms were grown on culture. A chest X-ray showed moderate cardiac enlargement, and an X-ray of her abdomen was normal. An electrocardiogram showed generalised non-specific T wave inversion: Immediate dialysis was necessary. It proved difficult in view of the patient's circulatory failure but ultrafiltration was achieved. Post dialysis her jugular venous pressure was $3 \mathrm{~cm}$. above the sternal ângle and she was much less dyspnoeic. She remained hypotensive for 8 hours: Fluids were restricted to $500 \mathrm{ml}$. in 24 hours, and a high calorie, low salt diet given. Durabolin $50 \mathrm{mg}$. i.m. daily, crystalline penicillin and codeine phosphate were also given. Her oedema lessened although her urine output was less than $1000 \mathrm{ml}$. daily (see Fig. 1). She had severe distressing diarrhoea which could not be measured because she was incontinent. Cystoscopy showed ulceration of the bladder, but retrograde pyelography was normal. She remained very ill and developed a severe oral monilial infection. An episode of atrial tachycardia with atrio-ventricular block was attributed to digitalis intoxication and was successfully treated with pronethalol.

Apart from a post-cystoscopy fever, her temperature was normal but leufcocytosis became more marked. (see Fig. 1). On the eighth day after , (n) 


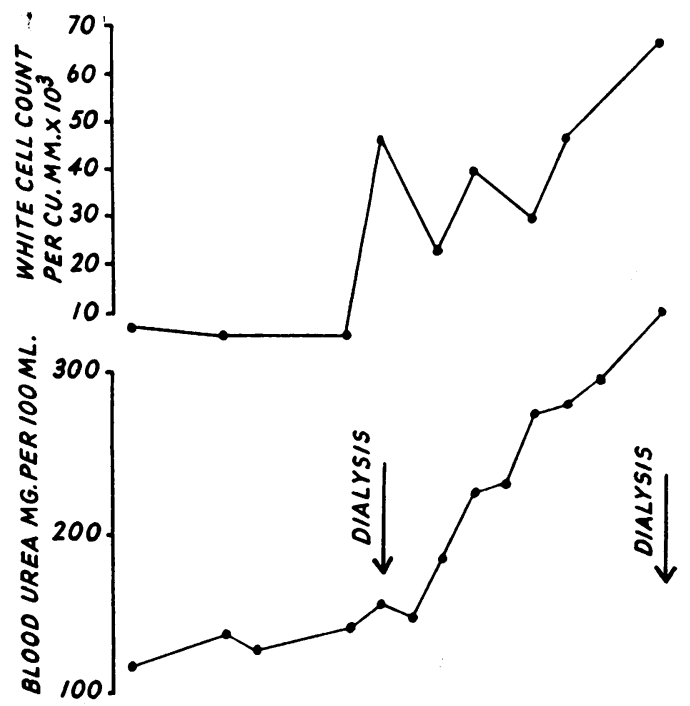

were swollen and pale and the cortico-medullary junction poorly defined. Histology of the pancreas showed extensive necrosis with acute inflammatory exudate and congestion. The kidneys showed generalised tubular necrosis affecting the convoluted tubules and changes of chronic pyelonephritis with minimal arterial and arteriolar thickening.

Case No. 4

A 62-year-old female was admitted to hospital on 21.1.65 with an 18-hour history of sudden onset of severe central abdominal pain and vomiting which had continued since.

On examination she was grossly obese, in pain and had a temperature of $100^{\circ}$ F. BP 200/120, pulse $94 / \mathrm{min}$., regular, and there were bilateral basal crepitations. Marked epigastric tenderness was present with guarding. Bowel sounds were present. Acute pancreatitis was diagnosed. Treatment by gastric suction and intravenous fluids was begun.

A plain X-ray of her abdomen was normal. $\mathbf{H b}$ $96 \%$, ESR $40 \mathrm{~mm}$./hr., WBC 11,000/cu. mm. (77\% neutrophils). Albumin, a few granular casts and white cells were present in the urine. Urine culture was sterile. Serum amylase 64 units $/ \mathrm{ml}$., blood urea 25 $\mathrm{mg} . / 100 \mathrm{ml}$. rising to $45 \mathrm{mg} . / 100 \mathrm{ml}$. the next day.

Over the next few days she continued to complain of moderate to severe central abdominal pain sometimes associated with vomiting. She remained very tender in the epigastrium with guarding. Her tachycardia continued though her pyrexia settled by 28.1.65. Severe epigastric and left hypochondrial tenderness and guarding were evident by 1.2 .65 and the presence of pseudopancreatic cyst questioned.

Operation. At laparotomy on 2.2 .65 marked patchy fat necrosis of the omentum with free sero-sanguinous fluid was found. The head of the pancreas was firm and swollen and there were many surrounding adhesions. A left sub-colonic drain was left in situ. Blood urea $325 \mathrm{mg} . / 100 \mathrm{ml}$, serum potassium 6.7 , bicarbonate $10 \mathrm{mEq} . / 1$, WBC 15,000/cu. mm. (78\% neutrophils). Her general condition deteriorated by 4.2 .65 when her blood urea was $330 \mathrm{mg} . / 100 \mathrm{ml}$. and 24-hour urine output $400 \mathrm{ml}$. and she was transferred to the Renal Unit.

On Examination she was drowsy with acidotic breathing, pulse $94 / \mathrm{min}$., regular, BP $180 / 80$, respirations $18 / \mathrm{min}$., temperature normal. Strawcoloured fluid was draining from the abdomen. The abdomen was distended and there were no bowel sounds. Blood urea was $375 \mathrm{mg} . / 100 \mathrm{ml}$., serum sodium 135 , potassium 6.7 , plasma bicarbonate 15 mEq./1. Hb 60\%, PCV 29\%, WBC 13,750/cu. mm. The plasma and urine osmolalities were 297 and 312 mOsm./kg. respectively. The urine urea was $950 \mathrm{mg} . /$ $100 \mathrm{ml}$. with a urine/plasma ratio of 2.5 . Serum amylase 264 units $/ \mathrm{ml}$. There was moderate albuminuria but no glycosuria or haemoglobinuria. The urine was sterile but there were a moderate number of pus cells seen on microscopy.

The patient was dialysed for six hours on the Kolff Twin Coil with good electrolyte adjustment. There was an exacerbation of symptoms during dialysis. Gastric suction, intravenous fluids and 'Trasylol' were given. There was considerable improvement over the next three days with recovery from the paralytic ileus and start of the diuretic phase. The patient relapsed on 10.2 .65 , once more developing paralytic ileus although a good daily urine output of over a litre continued. She died on 11.2.65.

Necropsy: There was complete autolysis of the 
pancreas, widespread fat necrosis in the abdomen and acute renal tubular necrosis.

\section{Discussion}

The diagnosis of pancreatitis may be difficult to prove or even be overlooked until necropsy as in the third case described. But it is more often recognised than formerly, partly from more frequent suspicion and partly because of available tests such as the serum amylase. Unless the possibility of acute renal failure complicating pancreatitis is appreciated, there is considerable risk of overtreatment by intravenous therapy as in two of our patients.

The value of serum amylase estimations in diagnosing pancreatitis in the presence of acute renal failure is difficult to evaluate. Elevated serum amylase levels unassociated with pancreatitis have been reported by Meroney, Lawson, Rubini and Carbone (1956) in acute renal failure. However, Beisel and others (1959) and Varay (1957) have reported considerable falls in the serum amylase level in acute pancreatitis complicated by renal failure in spite of continuing oliguria. It seems, therefore, that serum amylase levels are worth measuring on at least two occasions. However, Albo, Silen and Goldman (1963) found that $36 \%$ of their 133 cases uncomplicated by renal failure had a serum amylase level of less than 200 Somogyi units.

Whether pancreatitis or uræmia is the primary disease in such combinations has been questioned (Merrill, 1955, and Ducrot and Slama, 1960) but in the patients reported here there can be little doubt that pancreatitis was the primary disease. In all of them the abdominal disease preceded any renal failure and necropsy showed that the renal lesions were acute. The poor prognosis of this combination is well recognised. All five cases reported by Beisel and others (1959) died and Balslov and others $(1962)$ found a $78 \%$ mortality rate when reviewing the world literature.

The mechanism whereby renal failure complicates pancreatitis is difficult to unravel. Thal, Kobold and Hollenberg (1963) have studied vasoactive substances released into the circulation of patients with acute pancreatitis. They believe that when the pancreas is damaged, pancreatic enzymes are released and liberate potent vasodilator substances from globulin precursors in the plasma. These substances may affect capillary permeability but at all events a severe vasomotor collapse ensues and the hypotension is often sufficiently prolonged to cause renal failure. Our patients, however, did not suffer from hypotension before the onset of their renal failure. Hypercoagulability, which has been confirmed recently in acute pancreatitis by Shinowara, Stutman, Walters and Ruth (1962), does not seem to have played a part either in causing renal failure in these patients.

Methaemalbuminaemia (Webb, 1963) and haemoglobinuria (Gambill, Baggenstoss, Van Patter and Power, 1948) have been described in association with acute hæmorrhagic pancreatitis and have been suggested as contributory factors in causing acute renal failure. Haemoglobinuria did not feature in the cases reported but methaemalbuminaemia was not looked for.

Mirsky and Freis (1944) injected trypsin solutions intraperitoneally into rats and rabbits, and intravenously into rabbits. All the animals developed a profound shock syndrome and died, but there were no control animals. The necropsy studies of the kidneys showed cloudy swelling and vascular congestion with degeneration of cells in the convoluted and distal collecting tubules. There was massive deposition of eosinophilic granular and fibrillar material in the glomerular and tubular spaces with foci of lymphocytes around the distal collecting tubules and arterioles. The urine contained red and white cells but no hæmoglobin. However, î is not possible to attribute these effects to trypsin per se because of the profound hypotension following these injections. Reid, Paulette, Challis and Hinton (1958) using various pancreatic homogenates studied the effects of these on the oxygen uptake of kidney and other tissue homogenates. They found the oxygen uptake measured manometrically was depressed most markedly by the microsome fraction of the pancreatic homogenates. Pure pancreatic secretion after vagal stimulation had a marked inhibitory effect which was destroyed by heating at $95^{\circ} \mathrm{C}$ for 15 minutes. This would not destroy trypsin, suggesting that the inhibi tory effect on oxygen uptake is due to some other agent. This unidentified agent may be an important factor in producing acute renal failure by interfering with oxygen utilization by renal tubules. This could, in turn, explain renal failure occurring in patients with acute pancreatitis who have neither hypotension nor evidence of obstruction in small renal vessels.

Pancreatic homogenates have also been found to reduce the oxygen uptake of heart muscle (Reid and others, 1958). de Jode and Howard, (1962), suggest that the ECG changes that sometimes accompany acute pancreatitis may reflect the effects of activated trypsin in the 
circulation upon heart muscle. Pulmonary oedema indicating myocardial embarrassment is not an infrequent complication of acute pancreatitis and occurred in our patients. Case no. 3 also developed a fibrinous pericarditis which seems to have been related to her acute pancreatitis.

The evidence for implicating fat droplet emboli as the cause for renal failure in pancreatitis is poor. Lynch (1954) reported five such cases, but these were all post mortem studies and there was little supporting clinical evidence for acute renal failure. Furthermore, if emboli were the cause then a patchy rather than uniform distribution of the renal lesion would be expected, which is not the case. Circulatory enzymes and toxic tissue products would be more likely to cause the uniform renal lesions in the absence of hypotension.

Another contributory factor in the aetiology of renal failure complicating traumatic pancreatitis without hypotension is suggested by the laparotomy findings in case no. 1. Pallor and spasm of the small bowel had been found an effect of sympathetic nerve over activity. Sympathetic fibres supplying the small bowel and kidneys are intimately related at their origin in the coeliac plexus (Gray, 1954). Therefore in this case it is possible that intense sympathetic vasomotor activity was occurring in the kidneys at the same time as in the bowel, due to stimulation of the coeliac plexus following trauma. Such sympathetic vasomotor activity may have been sufficient and prolonged enough to cause renal anoxia in the absence of systemic hypotension.

Danker and Herfitz (1951) studied the creatinine clearances of patients with acute pancreatitis not complicated by any circulatory collapse. In some they found a reduction in creatinine clearance which was maximal at 24-48 hours and associated with an abnormal pattern of amylase excretion. This again suggests that some factor released from the pancreas or from plasma precursors may directly involve renal function in the absence of hypotension. It also shows how easily renal failure may be missed in these cases unless careful watch on urine volumes and specific gravities are kept.

Balslov and others (1962) pointed out that anticoagulation required for hæmodialysis did not cause an exacerbation of hæmorrhagic pancreatitis or increased tendency to retroperitoneal hæmatoma. Case no. 1, however, complained of severe abdominal pain during hæmodialysis associated with blood staining of the pancreatic fluid from the abdominal drain. It is felt, therefore, that regional heparinization should be used when dialysing such patients.

From our experience and those of others, it seems that careful control of the acute renal failure both by conservative management and hæmodialysis does little to alter the prognosis, although such treatment is necessary if the patient is to recover. Two of our patients survived for three weeks and one entered the early diuretic phase but all died from the underlying pancreatitis. Both increased enzyme activity and increased enzyme production have been found to occur in acute pancreatitis and conventional treatment of continuous aspiration of gastric and duodenal contents is designed to inhibit such secretion. The anatomy of the pancreas is such that it precludes pancreatectomy as a means of removing the source of enzyme production. It may be, therefore, that the administration "of a kallikrein-trypsin inactivator (e.g. 'Trasylol') from the onset of the disease may improve the prognosis in this group of patients. Many reports have already appeared showing that the mortality rate in acute pancreatitis not complicated by renal failure is reduced by using this inactivator. Though used in two of our patients, it was given late in the course of the illness and submaximal doses were used and no conclusions can be drawn with regard to its effectiveness in this situation.

\section{Summary}

Four patients are described who had acute oliguric renal failure unrelated to hypotension in the course of acute pancreatitis. The mechanism of such renal failure is discussed. The importance of appreciating the appearance of renal failure in the absence of known precipitating causes is stressed.

Our thanks are due to Dr. Clifford Hoyle, Director of the Medical Unit, for his encouragement and helpful criticisms in the preparation of this paper.

\section{REFERENCES}

Albo, R., Silen, W., and Goldman, L. (1963): A Critical Clinical Analysis of Acute Pancreatitis, Arch. Surg., 86, 1032.

Balslov, J. T., Jorgensen, H. E., and Nielsen, R. (1962): Acute Renal Failure Complicating Severe Acute Pancreatitis, Acta. chir. scand., 124, 348.

Beisel, W. R., Herndon, E. G., MYerS, J. E., and STONES, L. (1959): Acute Renal Failure as a Complication of Acute Pancreatitis, Arch. intern. Mred., 104, 539.

Blumenthal, H. T., and Probstein, J. G. (1959): Pancreatitis: A Clinical Pathologic Correlation, Springfield, Illinois: Charles C. Thomas. 
DANKNER, A., and Herfitz, C. J. (1951): Interrelationship of Blood and Urine Diastase During Transient Acute Pancreatitis, Gastroenterology, 18, 207.

DE Jode, L. R., and Howard, J. M. (1963): The Management of Patients with Acute Pancreatitis, Surg. Clin. N. Amer., 42, 1489.

Ducrot, H., and SLAMA, R. (1960): Les Insuffisances Renales Associées à une Pancreatite Aigue, Rev. méd.-chir. Mal. Foie, 35, 199.

EDLuND, Y. (1950): Acute Necrosis of the Pancreas, Acta, chir. scand., 99, 497.

Gambill, E. E., Baggenstoss, A. H., Van Patter, W. G., and Power, M. H. (1948): Acute Hæmorrhagic Pancreatitis: Study of Patient having Dessiminated Fat Necrosis, Hypocalcæmia, Hypopotassæmia, Uræmia, Diabetes Mellitus, Ascites and Bilateral Hydrothorax, Gastroenterology, 11, 371.

Gray's ANatomy (1954): Thirty-first edition, p. 1201, London: Longmans Green.

LYNCH, M. J. (1954): Nephrosis and Fat Embolism in Acute Hæmorrhagic Pancreatitis, Arch. intern. Med., 94, 709.

Meroney, W. H., LAwSON, N. L., Rubini, M. E., and Carbone, J. V. (1956): Some Observations of the Behaviour of Amylase in Relation to Acute Renal Insufficiency, New Engl. J. Med., 255, 315.
MerRILL, J. P. (1955): The Treatment of Renal Failure, New York: Grune and Stratton.

MirSKY, I. A., and FreIS, E. D. (1944): Renal and $\triangle$ Hepatic Injury in Trypsin "Shock", Proc. Soc. exp. Biol. (N.Y.), 57, 278.

Reid, L. C., Paulette, R. E., Challis, T. W., and Hinton, J. W. (1958): The Mechanism of the Pathogenesis of Pancreatic Necrosis and the Therapeutic Effect of Propylthiouracil, Surgery, 43, 538.

RUSSEll Taylor (1949): The Aetiology, Pathology, $\stackrel{\mathbb{Q}}{\varrho}$ Diagnosis and Treatment of Acute Pancreatitis, Ann. roy. Coll. Surg. Engl., 5, 213.

Shinowara, G. Y., StutMaN, L. J., Walters, M. I., and RuTH, M. E. (1963): Hypercoagulability in Acute Pancreatitis, Amer. J. Surg., 105, 714.

Siler, V. E., and Wulsin, J. H. (1951): Consideration of Lethal Factors in Acute Pancreatitis, Arch. Surg., 63, 496.

Thal, A. P., Kobold, E. E., and Hollenberg, M. J. (1963): The Release of Vasoactive Substances in $A$ Acute Pancreatitis, Amer. J. Surg., 105, 708.

VARAY, A. (1957): Retentissement Renal des Pancreatites Aiguës, Acta gastro-ent. belg., 20, 865.

WEBB, A. J. (1963): Hypocalcæmic Tetany and $₫$ Methaemalbuminæmia in Acute Fulminating Pancreatitis, Postgrad. med. J., 39, 361. 